\title{
Cultural Models of Raça: The Calculus of Brazilian Racial Identity Revisited
}

H. J. FRANÇOIS DENGAH II, Department of Sociology, Social Work, and Anthropology, Utah State University, Logan, UT 84322, USA.

Email: francois.dengah@usu.edu

JASON GILMORE, Department of Languages, Philosophy,

and Communication Studies, Utah State University

MARCUS BRASILEIRO, Department of Languages, Philosophy,

and Communication Studies, Utah State University

AN NA S. COHEN, Department of Sociology, Social Work, and Anthropology, Utah State University

ELIZABETH BINGHAM THOMAS, Department of Anthropology,

Southern Methodist University

JENN I BUDGE BLACKBURN, Department of Sociology, Social Work, and Anthropology, Utah State University

MCKAYLE LAW, Department of Anthropology, Northern Arizona University

JAE SWAINSTON, Department of Anthropology, University of Oklahoma

RICHARD THOMAS, Department of Anthropology, Southern Methodist University

Nearly 50 years ago, Marvin Harris published a seminal paper that examined how Brazilians create taxonomic categories of racial identity. In the intervening decades, new cognitive theories and analytical approaches have enabled researchers to investigate cultural domains with increased sophistication and nuance. In this paper, we revisit, replicate, and extend Harris's research by utilizing modern cognitive anthropological approaches such as multidimensional scaling and cultural consensus analysis. Utilizing the same facial portraits as in the original study, we ask a contemporary sample of 34 Brazilians to identify and sort these images by racial identity. We then compare Harris's original data, reanalyzed with modern techniques, to show that Brazilians had, and still hold, structured and coherent models of race. This finding has important social ramifications for race in Brazil and highlights the importance of replicability in the social sciences.

Key words: Brazil, race, cognitive anthropology, cultural models

Brazil is a melting pot of humanity, arguably unlike any other, and has been the focus of the anthropological gaze for more than 500 years (Brand 1941). A unifying theme between the first ethnographic accounts from Portuguese explorers to modern anthropologists is that of "race." The persistent interest in the classification schemes of this

Submitted September 13, 2017; accepted February 15, 2018; published online May 13, 2019. Journal of Anthropological Research (Summer 2019). (C) 2019 by The University of New Mexico. All rights reserved. 0091-7710/2019/7502-0002\$10.00 
South American nation should come as little surprise. In the process of nation making, Brazil holds the narrative that it is a "racial democracy," with no institutionalized barriers between people based on race. In support of this founding myth, Brazil celebrates its miscegenated social body in popular culture and national politics alike. One iconic example can be found in Brazil's national dish, feijoada. This stew of black beans, red meat, and white rice is colloquially purported to represent the three races of people: the African slaves, the indigenous tribes, and the Portuguese colonists who came together to make Brazil.

Nearly 50 years ago, Marvin Harris (1970) published a seminal paper on this calculus of Brazilian racial identity. In the intervening half-century, research on the racial classifications of Brazilians has both supported Harris's initial conclusion that "the most distinctive attribute of the Brazilian 'racial' calculus is its uncertain, indeterminate, and ambiguous output" (Harris 1970:1) as well as challenged its basic assumptions (see Bailey 2002; Loveman 1999; Yelvington 2001). In particular, Sanjek (1971), a student of Harris, argued that regional classifications were much more ordered and systematic than classifications across the entire country (see also Byrne and Forline 1997). Similarly, more recent scholars have suggested that racial typologies in Brazil are essentially bipolar, with a white-nonwhite dichotomy underlying the seemingly more fluid and contextual schema (Baran and Sousa 2001; Sheriff 2001).

Recent developments in ethnographic methods and analysis, particularly in cognitive anthropology, can shed new light on the puzzle of Brazilian racial categories. In particular, via the approaches of cultural consensus and cultural domain analysis, researchers are now able to apply tests that evaluate the amount of intracultural sharing around any cultural domain. Further, these modern analytical techniques also allow for reanalysis and replication of older, influential studies (e.g., Byrne and Forline 1997).

Utilizing the same methodology as Harris's original study, but with more current analytic tools, our primary objective in this paper is to explore whether contemporary Brazilian Bahians of the nordeste (northeast region) have a distinct cultural model of racial types, or whether they perceive race as a fluid, fuzzy, and ambiguous concept. In line with recent research, we argue that Bahians do have a shared cultural model of race, which is essentially constructed along a black-white color (cor) divide. As a secondary objective, we also extend modern cognitive anthropological analytics to Harris's original data to examine how our recent findings compare with Harris's work 50 years ago. Beyond providing a point of reference for this current research, this provides an example of replication of an anthropological study-something of concern in the social sciences (LeCompte and Goetz 1982; Freese and Peterson 2017).

In this article, we revisit, replicate, and extend Marvin Harris's study on cultural models of race in Brazil. First, we provide a discussion of racial typology and meaning in Brazil, followed by a brief review of cognitive anthropological theory and method. Second, we discuss recent cognitive anthropological studies of race, particularly those that utilize the same methodology as outlined by Harris. Third, we consider a reanalysis of the data in Harris's 1970 article by utilizing modern cognitive anthropological 
analytical techniques. In doing so, we create a reference point for comparison with our more recent research. Fourth, we present this new data, which we collected by asking 34 Bahians to identify and sort the same facial portraits used in the original study by shared racial identities. Utilizing cultural consensus analysis and multidimensional scaling, we are able to determine both the amount of cultural sharing present, as well as the composition of Brazilian racial taxonomies. Importantly, other than Harris and his student, Sanjek (1971), there have been few studies on Brazilian emic racial classifications employing this particular approach. As a result, this paper provides an opportunity to demonstrate the replicability of cognitive anthropological methods to both old and new data. We conclude by discussing the meaning of racial classification in contemporary Brazil, drawing from the life experiences of some of our informants.

\section{BACKGROUND}

For more than a half century, research on Brazilian racial classification has fluctuated between characterizing racial categories as fluid and ambiguous (e.g., Harris 1970; Kottak 1967; Wagley 1952) to more rigidly defined and essentialized (e.g., Jones 2009, Sheriff 2001). Even while recent research has tended to favor more binary, black-white color divides within Brazilian society, recent studies have also highlighted the intermediary, indetermination, and contextual aspects of race in Brazil (see Baran 2007; DaMatta 1997). Indeed, few people who travel to Brazil can ignore the paradox of Brazil's discourse of being a democracia racial (racial democracy) with seemingly rigid race-class boundaries that divide society (Robinson 1999). Below, we provide a background to this Brazilian puzzle, including a brief recapitulation of Harris's seminal research on this topic, alongside subsequent efforts to extend and replicate his initial study.

\section{Race in Brazil}

As seen in the myth of "racial democracy" and the symbolic meaning of feijoada, race and the notion of racial fluidity is a fundamental part of Brazilian national identity. As a result, the Brazilian taxonomy of race is something that has interested native and foreign scholars. In part, this is because there appears to be a fundamental contradiction between what is possible and what is in terms of racial identification. Some of this discrepancy lies in the two Brazilian terms alternatively used to describe "race": cor (color) and raça (race or breed). These terms are sometimes used interchangeablyin government documents, for example. Cor is more frequently applied to denote phenotypic appearance and social status, and it approximates most closely with the term "race" used in the United States. In contrast, raça is generally associated with animal breeds rather than with human groups, and the term implies genetic ancestry (Skidmore 2009). Importantly, however, the subtle definitional differences between cor and raça have been changing over time, with increasing conflation of the two terms. Institutionally, the Brazilian government equates the two terms, and since 1991 the census has used both when inquiring about one's racial identity (Ferreira 2012). Recently, 
raça is also increasingly being used by scholars and others to imply historically shared community identifications, rather than strict biological descent (see Ferreira 2012; Guimarães 2003).

The confusion between cor and raça has much to do with the historical uniqueness of Brazil and the emphasis on embranquecimento (whitening). Embranquecimento was once a political plan that the government hoped would "civilize" Indigenous and Afro-Brazilians by diluting their genetic stock through interbreeding. In 1823, Brazilian Minister of the Empire (prime minister) José Bonifaácio de Andrada e Silva wrote that miscegenation will "make of them all one sole body of the nation, stronger, better educated, and more entrepreneurial” (Holston 2008:68). This plan ushered in a European immigration rush and all but codified the belief that "whiteness" was equated with civility, beauty, and morality. Thus, unsurprisingly, only $5-6 \%$ of modern Brazilians self-identify as negro (black) despite more than $50 \%$ of the population having some degree of African heritage, though this trend is changing (Skidmore 2009).

Census data also reflect that the population at large has oscillated between traditional ideas of cor and of raça. In an analysis of census data from the mid to late twentieth century, Wood (1991), Carvalho et al. (2004), and Telles (2014) found that the population of negros declined by as much as one third, and the numbers of pardos (brown or mixed-cor) increased, more than doubling from $21 \%$ to $43 \%$ of the total population. This phenomenon may be attributed not only to miscegenation, but to a large-scale self-reclassification from black to brown that was facilitated by embranquecimento and economic development. Yet, in the closing decade of the twentieth century, the number of Brazilians identifying as morenos ("browns") and pardos decreased, and the number of negro Brazilians increased by a third (Miranda 2015). Researchers suggest that this change is not due to changes in mortality, migration, or census coverage, but to another large-scale self-reclassification. This time, Brazilians adopted a more essentialized raça framework (i.e., genetic heritage) for self-identification (see also Ferreira 2012). The replacement of cor for raça within Brazilian discourse has multiple origins, including in grade school classrooms; the increased valuation of black identity facilitated by the Black Movement (particularly in the nordeste and in Afro-Brazilian cultural centers such as Salvador); and even in the portrayal of characters in telenovelas (Baran 2007; Soares 2008). The Brazilian economist Sergei Soares (2008:116) aptly sums up this change in identity: "What is happening is not that Brazil is becoming a more Black nation, but it is identifying itself as such." (Given the more recent use of the term of raça, as well as Harris's preference for the word in his original research, we similarly use the term in our own more recent study of Brazilian cultural models.)

Practically, the ways by which Brazilians talk about and invoke racial identities is context-specific and can greatly differ between etic-emic and self-described/ascribed classifications (Sheriff 2001). For instance, constrained etic categories of color-race may have drastically different results depending on the categories offered. Byrne and 
associates (1995) found that even though pardo and moreno both describe the same phenotypic appearance, individuals may identify with one and not the other. When self-ascribed morenos were forced to choose between branco, pardo, and negro, only $27 \%$ identified as the technically equivalent term, with the rest roughly splitting between branco and negro. Different racial typologies may also be selectively employed in certain social situations and with certain individuals, focusing on fluid identifications, social context, and subtly/explicitly injecting respect or disrespect (see also Hordge-Freeman 2015). For instance, both preto and negro apply to an individual with dark skin and African facial features. Yet, some communities prefer one or the other, depending on the setting. Preto, a cor-oriented term, is the official government term but may additionally connote lower socioeconomic class. Negro, implying raça, can also be considered insulting but is being reappropriated by the Black Movement (Movimento Negro Unifcado, MNU), and it encompasses both black and brown-skinned Brazilians (essentially bifurcating the population into white and nonwhite) (Bailey et al. 2013). Illustrating this point, Mikulak (2011:80) highlights one respondent, who self-identified as both negro and preto, as stating:

preto and Negro are the same words ... only Negro is a moreno that is a little lighter, but Negro and preto are the same thing . . . [but] preto is a very pejorative term ... so, if someone calls me preto, I say that I'm not preto, I'm Negro.

Later, Mikulak (2011:81) recalls the words of another informant, who more explicitly links preto and negro with very different associated phenotypic and social characteristics:

[Preto] is associated to bad things, to what may be forgotten - preto is dirty it's different from saying Negro, you say 'preto' and you are meaning something that is of little importance, that is pejorative, less intelligent, poor, ugly - well, you know, the mouth, the nose, the hair.

Thus, for many Brazilians (the MNU notwithstanding), there is a conscious calculus to self-identify as lighter (see Burdick 1998; Edmonds 2010).

Indeed, while the myth of "racial democracy," miscegenation, and dozens of colloquial color categories (e.g., a 1976 national survey recorded 134 unique terms, including everything from "coffee with milk" to "after midnight"; see Bailey 2009) allow people to (seemingly) eschew rigid racial categories, and self-describe more variously, there is still an underlying dimension of whiteness equating with "better." For instance, in a study on racial identification, self-described moreno Brazilians, when confronted with a binary choice between white and black, overwhelmingly chose the former (Bailey 2008). Further, it is common for Brazilian women in particular to modify their appearance via hair straightening, skin whitening, and even plastic surgery so that they might be classified as morena instead of negra (Baran 2007; Edmonds 2010). With such av- 
enues for fluidity and alteration, it is unsurprising that there is often a distinction between self-identified and ascribed racial identities. In the 2002 national survey (Brazilian Social Survey), only $75 \%$ of respondents were self- and interviewer-classified as the same cor (along a ternary cor scheme: branco, pardo, preto). Brancos were most commonly identified the same by both the individual and interviewer $42.8 \%$ of the time, followed by pardos at $25.9 \%$. Yet, only $6.5 \%$ of the time did the individual and the interviewer agree on a classification of negro (Bailey et al. 2013).

Some of the discrepancy between self- and ascribed identification may lie in the associated social characteristics that factor in the construction of Brazilian racial categories. In what has been described as the "mulatto escape hatch," and reaffirmed in the common phrase "o dinheiro embranquece" ("money whitens"), social status allows people to identify as a lighter cor based on their wealth, education, employment, and related characteristics (Bailey et al. 2013). For instance, Schwartzman (2007) finds that increased education levels result in a greater probability that nonwhite parents will lighten and whiten the cor of their children. Similarly, Telles and Lim (1998) document that third-party individuals ascribed lighter skin color to those of higher socioeconomic status, and dark cor to those of lower status. In general, however, such attempts at whitening provide modest movement in terms of cor, relying on the "ambiguous and unstable nature of boundary between black and brown categories, in contrast to the (relatively stable and unambiguous) boundary between white and nonwhite" (Bailey et al. 2013:108).

Overall, the contrast between white and nonwhite, and the relative inability/rarity for someone to move between negro and branco classifications, has led many researchers to contend that the Brazilian racial calculus is much simpler-essentially a bipolar, hypodescent classification scheme (e.g., Fry 2000; Hasenbalg 1985; Sheriff 2001; Silva 1985). That is, while there may be colloquial fluidity around self- and ascribed identifications, Brazilians order their society along white-black color lines. Yet, others argue that for the majority of Brazilians, cor identity lies between the extremes, and the racial calculus is much more fluid and contextual. Commenting on this matter, Baran (2007:387) questions the existence of a singular, essentialized model:

These [cor] terms can shift meaning with context and speaker, they occasionally overlap, and many of them can be used to describe the same person. While this does not necessarily demonstrate a lack of essentialism, it does violate one of the common features of essentialism: the tendency for words to map directly onto the natural kinds attributed to the social world.

Importantly, the composition of cor categories, and their stability and use within Brazilian racial calculus, are empirical questions that can be tested. Using statistical and analytical techniques not available until recently, this paper reexamines Harris's data to look for significant patterns and compares them to recent original data collected by the authors during an ethnographic field school. 


\section{Cognitive Anthropology}

This paper applies cognitive anthropological methods to both old and new data, and it is thus important to review some key tenets and approaches. Cognitive anthropology focuses on how cultural knowledge is structured and shared among members of a community. "Culture" here refers to the systems of knowledge necessary to function within a social and/or ecological setting (D'Andrade 1995; Holland and Quinn 1987; Shore 1996). Units of cultural knowledge are variously conceptualized as prototypes, models, and schemas, which provide common frameworks for people to individually understand and jointly communicate their experiences of reality_including "racial" categories.

Cultural models might not be homogeneous or uniformly distributed among a population. There may be contention: alternative models can shape alternative cognitions and behaviors, which can result in conflictions and/or negotiations on the part of community members (see Dengah 2014; Dressler et al. 2015; Hruschka et al. 2008; Snodgrass et al. 2011). Such variation between individuals and subgroups is necessary for social learning, innovation, and culture change. For example, as discussed above, more individuals today identify as preto or negro, which reflects an increasing adoption of the cultural models related to black consciousness.

The qualitative and quantitative methods that lie at the heart of cognitive anthropological research are as varied as the topics studied. For instance, schema analysisthe evaluation of common and salient ideas_can be applied to unstructured and semistructured interviews. Cultural domain analysis - the analysis of cognitive "lists" relies on more structured methods such as free listing, identification, and pile sorting tasks. In this study, we focus specifically on cultural domain analysis to ascertain the structure of Brazilian racial taxonomies and cultural consensus analysis to determine the degree to which informants share these models (see below). The point here is not to provide an exhaustive description of cognitive anthropology (see, for example, Bernard 2011; Bernard and Gravlee 2014; D’Andrade 1995), but rather to provide a brief background of the cognitive anthropological approach.

\section{HARRIS'S RACE STUDY AND RELATED RESEARCH}

This study not only replicates and extends Harris's racial pile sort methodology with new statistical techniques, we also employ newer analytical approaches in the reanalysis of Harris's 50-year-old study. Below, we review Harris's original research in depth, as well as some subsequent adoptions of the racial pile sort methodology.

In order to identify the cultural model of Brazilian race, Harris (1970) created a set of cards that contained 72 assorted facial drawings that varied along several dimensions. The drawings systematically contrasted phenotypic composition, including gender (male and female), skin color (three tones), hair form (straight, wavy, kinky), nose width (narrow, wide), and lip size (small, large). Since the drawings depicted differing facial characteristics while keeping other features constant (in contrast to photographs of actual people), Harris hoped to identify the specific phenotypic trait(s) that 
distinguished the dozens of Brazilian racial terms from each other. Sampling 100 adult Brazilians from across Brazil, including Bahia, Brasilia, and São Paulo, Harris asked each respondent to identify the raça of each face in the deck.

Harris's sample netted 492 different categorizations for the 72 face cards. Twentyfive percent of the informants provided 15 or more different terms to describe the faces, with a range spanning 2-70 terms and a median of 9 terms per respondent. Somewhat to Harris's surprise, each card was identified by no less than 20 terms each, though many of these were derivatives of a common root term (e.g., moreno [brown] and moreno claro [light brown]). Yet, despite the abundance of racial terms, Harris (1970:3) suggests that this does not mean that cultural models of race are a "totally orderless domain." That is, there are some clear, prototypical categories along the poles (i.e., negro and branco) of variation that do show "order." In his estimation, however, the majority of the faces, particularly those of intermediate skin and facial characteristics, show the “pronounced tendency towards ambiguity" (Harris 1970:3).

In order to more systematically look for any patterned order or ambiguity of cognitive-cultural racial categories, Harris reduced his analysis to only the most commonly employed terms. Lacking modern multidimensional scaling methodologies, Harris opted to graph the frequency by which certain face drawings were identified with a particular racial category. Again, he found that the poles demonstrate clearer cognitive model patterning, particularly concerning branco/preto categorizations, and respondents identified certain cards as either branco or preto, but never both. Harris also attempted to look for other correlations of racial categories. He found general patterns, such as branco and alvo (white, clean) being highly correlated with one another, but not synonymous. A great many of the terms varied by no clear patterning with any other race term, leading Harris (1970:12) to lament that:

If there is an orderly principle by which morenos or mulatos are distinguished from brancos, pretos, sararás, alvos, claros, and cabo verdes, it is an extremely complex one. At the moment it seems as if Brazilians will call almost any combination of facial features by the terms moreno or mulato with a high but unpatterned frequency.

Harris (1970:12) cited this lack of clear patterning as proof that there are some weaknesses in the "assumptions about cognitive domains now popular among anthropologists." Commenting on what was called the "New Ethnography" (a predecessor to today's cognitive anthropology), Harris challenged the idea that culture creates uniform intersubjective classes of phenomena. Instead, he argued that the entire Brazilian conception of race is to maximize noise and ambiguity. In other words, there is consensus about the lack of consensus. For Harris, this was visible in the data, but also in the national myths of "racial democracy" and in the historical facts of miscegenation.

Several other researchers have utilized similar techniques for their analyses of racial categories. Soon after Harris's original study, Sanjek (1971) used the same face draw- 
ings in Sitio, a fishing village north of Salvador, Bahia. Sanjek, like Harris before him, lacked access to modern statistical techniques to examine patterns of cultural knowledge. Instead, he applied a measure of "saliency" to look for shared and common responses to each of the cards, or the percentage of time respondents used a racial root-term for a particular card. Unlike Harris, Sanjek found patterning of race terms based on skin color and hair in all of the drawings (see also Jones 2009). Light skin and straight hair were associated with branco and alvo; dark skin and straight hair, with cabo verde (dark skin with Caucasian features) and caboclo (indigenous descent); light skin and kinky hair, with sarará and araçuabo (light skin with African features); and dark skin and kinky hair, with preto and negro. Terms such as moreno and mulato (the latter being a mixture of branco and negro) represented intermediate forms, particularly regarding hair and skin color. Sanjek concluded that the discrepancy between his and Harris's findings was due to the different sampling methodologies: Harris's informants were from across Brazil, whereas Sanjek's were recruited from a single village.

Later analysis of Harris's data does suggest that regional differences may have obscured racial categorical patterning (see Byrne and Forline 1997). Utilizing data provided by Harris, Byrne and Forline (1997) conducted cultural consensuses analysis to look for a common cultural model of Brazilian race. Since its introduction by Romney, Weller, and Batchelder in 1986, cultural consensus analysis has become a mainstay within cognitive anthropological research (see Dressler 2017; Lacy et al. 2018). Briefly, the cultural consensus approach posits that shared cultural knowledge will manifest as a significant agreement between informants around a cultural domain. Via factor analysis of informant responses (performed by various computer programs, such as Anthropac or UCINET), consensus is defined as (1) the first eigenvalue ratio explaining three times the variance as the second eigenvalue and (2) average informant loadings on the first factor (i.e., competency scores) above 0.5 , with few to no negative individual competency scores (see Weller 2007). When Byrne and Forline (1997) applied this analysis to Harris's data, they initially found no evidence of consensus, supporting Harris's conclusion that Brazilian racial taxonomy was ambiguous. In contrast, when they analyzed responses from different Brazilian states, there was evidence of consensus, especially from states in Brazil's nordeste region (e.g., Bahia, Pernambuco).

Recent studies elsewhere in Latin America have also utilized Harris's face drawings, though combined with modern analytic methodologies. Clarence Gravlee's (2005) research on the cultural models of color in Puerto Rico represents the first time that multidimensional scaling methodologies were applied to Harris's race drawings. Following the same procedure as Harris, Gravlee added an additional pile-sorting task during which informants created piles of faces whose cor (rather than raza or raça) they thought were similar. Successive pile sorts created a similarity matrix between each of the faces, which were graphed in two-dimensions (or more) to show similarities and differences as a function of spatial coordinates (i.e., multidimensional scaling, or MDS). In Puerto Rico, Gravlee found five racial groupings distinguished by both skin color and hair form: indio, trigueno, blanco, negro, and jabao. In Venezuela, how- 
ever, Gulbas (2013) used the same approach as Gravlee and found only three cor clusters: moreno, negro, and blanco, which were largely determined along the dimensions of skin color and hair form. Gulbas also found that lip and nose shape did play a role, though in more subtle ways. Informants would be more likely to describe a face with a wider nose and thicker lips as darker, regardless of skin color and hair type. Despite these examples, Harris's approach for studying cultural models of race has not been widely applied in the field, let alone in Brazil (see Byrne and Forline 1997; Gravlee 2005). The techniques employed by Gravlee and Gulbas in Puerto Rico and Venezuela will be the approach we employ in our reanalysis of Harris's data, as well as our recently gathered data in Salvador, Bahia.

In summary, Harris's initial study on the calculus of racial typologies in Brazil was groundbreaking. Not only does it represent the first systematic attempts to study Brazilian racial typologies, it is also an early example of ethnoscience/cognitive anthropological methodology. Although Harris did not initially find evidence of widespread "consensus," he did argue for an ambiguous white-black divide. Subsequent studies, performed by Sanjek and others, suggest that while fluidity exists, the structure of racial categories may be much more coherent—-something obfuscated by the multiregional approach taken in the initial study. A benefit of cognitive anthropological approaches in general and of Harris's methodology in particular is that it avails itself to both reanalysis and replication. In the remainder of this article, we extend Harris's study by applying recent analytical techniques in cognitive anthropology to determine whether Brazilians have a clear racial typology and, if so, the nature of these categories.

\section{REANALYSIS OF HARRIS'S DATA}

We rely on the data published in Harris's (1970) article. As described above, Harris solicited racial or raça terms for each facial drawing from 100 informants. In the manuscript, he assigns each card a number (1-36 for men; women were not included in the published analysis) and provides the frequency that each card was associated with a particular category. Specifically, Harris constructed graphs showing the frequencies for eight of the most commonly utilized root categories: branco, preto, alvo, claro, cabo verde, sarará, moreno, and mulato. With this type of data, via multidimensional scaling, one can assess the frequency that a specific face card was labeled a specific term in relation to all other categories and cards. Briefly, multidimensional scaling is a common cognitive anthropological technique that is similar to factor analysis in that both can represent data in multidimensional space, where the distance between any two variables is inversely proportional to their similarity (Brazill and Grofman 2002). Using the PROXSCAL MDS routine available in SPSS v. 20, we are able to construct a proximity matrix using the raw count data presented in Harris's article, which we analyzed using this method.

Stress is a "badness-of-fit" measure that quantifies the amount of distortion present in the MDS diagram. Higher stress values indicate that there may not be a patterned relationship between the objects being diagramed in the chosen number of dimensions 
(Sturrock and Rocha 2000:50). As a rule of thumb, a two-dimensional MDS that contains 36 objects should have a stress below 0.343 to be significant at the 0.01 level (see also Dugard et al. 2010).

Figure 1 shows the multidimensional scaling of Marvin Harris's (1970) data, suggesting that even while Brazilian racial calculus does not reach "consensus" (see Byrne and Forline 1997), there is meaningful order within this domain, possibly representing a domain of "weak agreement" (see Caulkins and Hyatt 1999). Each dot represents a specific face card, with dots spaced closely together signifying commonly ascribed terminology. The six clearly identifiable groups correspond to Harris's a priori groupings: (clockwise) sarará, branco (with the alvo/claro subcategory), mulato, cabo verde (with two intermediate faces), moreno, and preto. Interestingly, the variables are arranged along two dimensions - a primary dimension for skin color and a secondary dimension for hair type. Unfortunately, Harris randomized the card numbers, and without knowing the actual standardized characteristics of each card, we could not conduct formal analysis of the dimensions (also known as Property Fitting Analysis, or ProFit). Re-

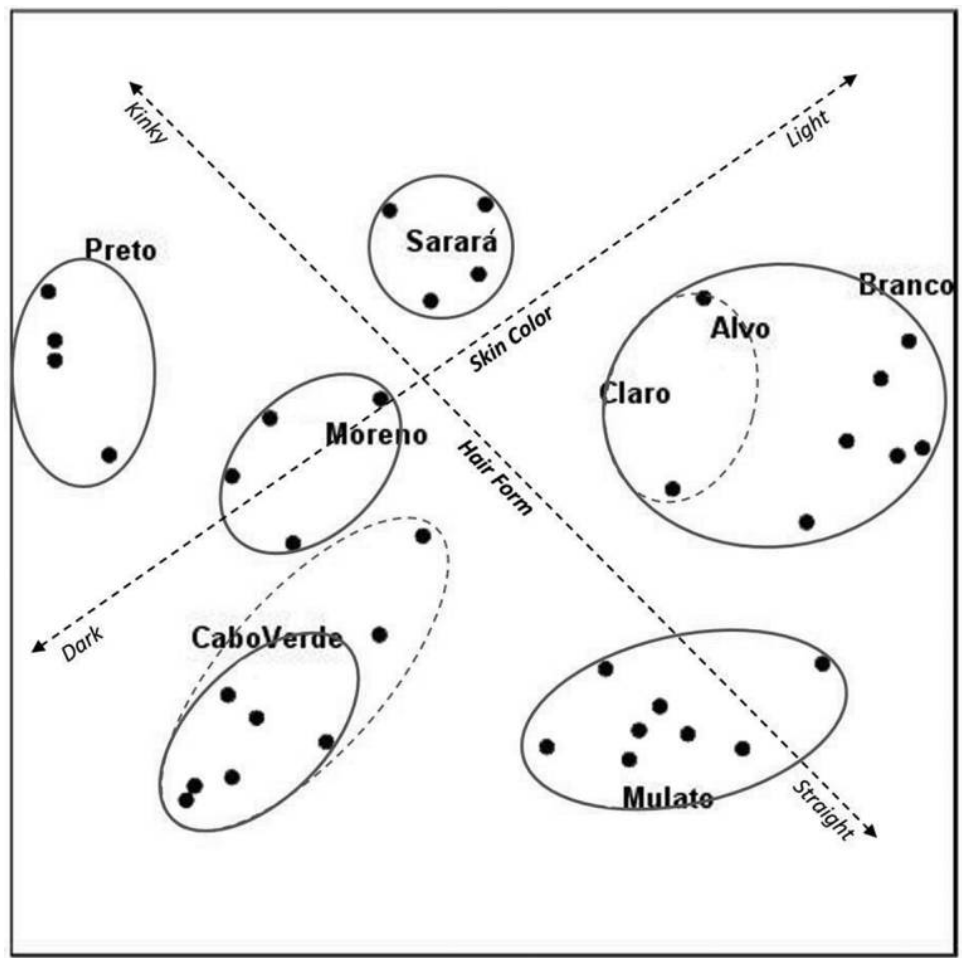

Figure 1. Multidimensional Scaling (MDS) of Harris's (1970) data with possible dimensions. Two-dimensional plot of 36 male faces sorted by Harris's informants (stress $=0.136$ ). Each dot represents a unique face card, with clusters encircled by solid lines and subclusters by dotted lines. 
gardless, the diagram shows very low stress (.136), indicating that the groupings are unlikely due to chance and that the data are a good fit in this form.

\section{BAHIA STUDY}

The next study was part of an interdisciplinary field school focusing on ethnography and communication studies. We conducted this research over three weeks in Salvador, Bahia, between June and July 2016. Salvador is the former colonial capital of Brazil. Founded by the Portuguese in 1549, it is located in the northeast of the country, just south of the bulge of Brazil, along a peninsula that separates the Baía de Todos os Santos (Bay of All Saints) from the Atlantic Ocean. Due to Salvador's proximity to both Europe and Africa, it became an important center of trade and commerce, including the trans-Atlantic slave trade. Salvador was the site of the first slave market in the Americas, and most of the estimated 5 million slaves who were brought to Brazil ( $40 \%$ of all slaves in the Western Hemisphere) came through Salvador's harbor before being sent to plantations elsewhere in the Americas. Because of this legacy, Bahia has become a center of Afro-Brazilian heritage, and most of the population has African roots. A recent Brazilian census found that $52 \%$ of the city's 2.9 million inhabitants identify as pardo, or mixed-race, and $28 \%$ as negro (IBGE 2010).

\section{Methods}

In this research, we followed the procedures used by Gravlee, which extends Harris's original study through modern cultural domain analysis. Working in and around the city center in Salvador, we interviewed 34 Bahians selected to represent a wide distribution of age, socioeconomic status, gender, and racial identity. In previous studies, sample sizes as small as 20 individuals were adequate to show the structure of coherent domains (Gravlee 2005). Also, sampling for such cognitive anthropological methods need not be random (Handwerker 2001, 2002). Collection of data on shared cultural knowledge requires a selection of informants who are integrated within the cultural group and knowledgeable about a specific domain. That is, because the purpose of these methods is to elicit shared cultural models, individuals should be carefully chosen for their cultural expertise as it relates to the research hypothesis and the cultural domain of focus (Handwerker 2001; see also Gravlee 2005). Informants were chosen to represent a range of ethnic and social class identities.

Following the procedure outlined by Harris, we first gave informants the set of 72 face drawings and directed them to look through the deck to familiarize themselves with the images. Next, we showed informants each card one at a time and asked them to identify the raça of the individual. Following the elicitation of terms for each of the 72 cards, we asked informants to sort the faces into piles of individuals with similar racial identities. In this latter task, the only stipulations were that the informant not make a single large pile or sort each card into its own pile. Informants were encouraged to think aloud and were asked the meaning behind their piles. These data were compiled into proximity matrices and analyzed in Visual ANTHROPAC (Borgatti et al. 
2002) for cultural consensus (a form of factor analysis that creates an informant-byinformant similarity matrix to determine if significant similarities or consensus exists among respondents, see Romney et al. 1986) and graphically displayed with multidimensional scaling.

\section{Results}

Our respondents represent the diversity of Salvador: the average age is 34.37 years (1854), 50\% are female, and $47 \%$ identify as negrolpreto, 29\% pardo, 12\% branco, $6 \%$ morenolmulatto, and $6 \%$ other. They work in a variety of professions, including sanitation worker, food vender, fisherman, hairdresser, student, manager, and college professor, and they occupy a range of economic brackets (averaging 4 times the minimum wage per month [the minimum wage $=\mathrm{R} \$ 880 /$ month, or approx. US\$228], with a range of $0-13$ times the minimum wage).

On the first task, the informants generated 62 different terms to describe the 72 faces. On average, each respondent listed about seven unique terms, with a range between two and eighteen. Although this list is much smaller than Harris's 492 terms and Sanjek's 116 terms (solicited by raça), it is comparable with Gravlee's (2005) 51 terms (using this methodology) and Jones's (2009) 49 terms (from 100 photographs). As in these other studies, most of the terms are derivatives of a common root term; for example, moreno-escuro (dark brown) and moreno-clara (light brown) are derivatives of moreno. When similar terms were combined, as shown in Table 1, 14 root

Table 1. Frequency of free list raça terms by categorizations $(N=2232)$, informants $(N=34)$

\begin{tabular}{|c|c|c|c|c|c|}
\hline \multirow[b]{2}{*}{ Brazilian term } & \multirow[b]{2}{*}{ English translation } & \multicolumn{2}{|c|}{ Categorization } & \multicolumn{2}{|c|}{ Informants } \\
\hline & & $\%$ & $n$ & $\%$ & $n$ \\
\hline Negro + & Black & 32.88 & 805 & 91.18 & 31 \\
\hline Mestiço + & Mixed & 16.63 & 407 & 61.76 & 21 \\
\hline Branco + & White & 15.60 & 382 & 91.18 & 31 \\
\hline Mulatto + & White and Black & 7.56 & 185 & 41.18 & 14 \\
\hline Indio/Nativo/Caboclo+ & Indigenous & 6.29 & 154 & 58.82 & 20 \\
\hline Moreno + & Brown & 6.09 & 149 & 32.35 & 11 \\
\hline Pardo + & Brown, Mixed & 6.05 & 148 & 32.35 & 11 \\
\hline Preto + & Black & 0.86 & 21 & 8.82 & 3 \\
\hline Sarará + & White skin, African features & 0.74 & 18 & 11.76 & 4 \\
\hline Cafuzo & Black and Indigenous & 0.61 & 15 & 8.82 & 3 \\
\hline Misturado + & Mixed & 0.41 & 10 & 8.82 & 3 \\
\hline Mameluco & White and Indigenous & 0.20 & 5 & 5.88 & 2 \\
\hline Cabo Verde & Dark skin, Caucasian features & 0.20 & 5 & 5.88 & 2 \\
\hline Oriental/Amarelo + & Asian & 0.20 & 5 & 8.82 & 3 \\
\hline
\end{tabular}

A “+” signifies categories in which derivatives were combined with their root term(s). 
terms comprise nearly $95 \%$ of all responses (indio, nativo, and caboclo were combined because several informants used the terms interchangeably, as were oriental and amarelo [yellow]). In fact, the top three terms—negro, mestiço, and branco-account for two-thirds of the racial identifications, with $91 \%$ of informants listing branco and negro and a smaller, though still substantial, percentage (61\%) using the term mestiço at least once. Thus, despite Brazil's reputation for having dozens and dozens of racial categories (see Harris and Kottak 1963), our informants seem to have a relatively small set of core racial types, upon which other qualifiers are added (e.g., escuro, claro) (see also Telles 2003).

Our identification task also shows evidence of culture change when compared with Harris's and Sanjek's data sets. The most striking modification is the increased use of negro in our sample, as compared with those collected 50 years ago. Synonyms for "black," such as escuro and escurinho, have largely disappeared from use. In fact, only three of our informants self-identified as preto, whereas thirteen identified as negro. This likely reveals the successful reappropriation of this term and the increased consciousness of negro identity in this part of Brazil. Our identification task also finds a fair number of people using (as well as self-identifying as) pardo. This term was absent from both Harris's and Sanjek's research but has seen increased usage over the decades. The linguistic alterations we see in our research are mirrored in Jones's (2009) work, which finds similar vocabulary changes in identification of photographs.

Following the procedure outlined by Byrne and Forline (1997), we performed cultural consensus analysis on the racial identification given to each of the 72 portraits, across our 34 informants. Via UCINET v.6 (Borgatti et al. 2002), we performed a "multiple choice" cultural consensus analysis, utilizing the aggregated racial terms identified in Table 1. Again, convention states that "cultural consensus" is supported when the eigenvalue ratio of the first to second factor exceeds 3, with an average competency of 0.5 , and no negative scores. Our analysis returned an eigenvalue ratio of 3.25 with an average competency score of 0.53 , and no negative loadings. Importantly, cultural consensus analysis can provide an estimated "answer key" - that is, the most culturally appropriate responses, determined by the competency-weighted answers of respondents (Weller 2007). Here, we see that the answer key identifies $85 \%$ of the facial portraits as either branco or negro. Five cards were identified in the answer key as indio and six as mestiço. Subsequent cross-tab analyses find that skin color (specifically white-branco) and hair type (kinky-negro) significantly predicted consensus designation at the .001 level. This result supports the evidence of Sheriff (2000), among others, that racial categories are essentially ordered along a black-white divide. However, consensus does not signify that the domain is without variation. Mirroring Harris's findings from 50 years ago, we find evidence that while some faces are nearly exclusively identified as either negro or branco, other faces revealed substantial disagreement and ambiguity (e.g., the 27 faces that failed to reach a third plurality are less likely to be white-skinned or have kinky hair). 
On the second task, informants completed an unconstrained pile sort to create groups of faces who share a similar racial identity. Figure 2 shows the results of the multidimensional scaling of the compiled similarity matrices.

Again, spatial distance is a measure of emic (dis)similarity since items frequently sorted together are represented in clusters, whereas items rarely or never sorted together are separated by increased distance. This figure represents the combined pile sorts of 31 informants (two informants insisted on creating a single pile for all the cards, remarking "they are all human beings," and "they are all mixes of every race," while another informant created separate groups for each card, similarly explaining "they are all unique individuals"). There are five clusters clearly visible in the MDS. In general, informants described these groupings as (clockwise in Figure 2) negro, mestiço/indio, moreno, branco, and sarará. Using PROFIT analysis, we are able to test the hypothesized dimensions of the MDS by regressing attribute values onto the coordinates. Skin color $\left(\mathrm{R}^{2}=0.71, p<0.001\right)$ and hair form $\left(\mathrm{R}^{2}=0.65, p<0.001\right)$ are the primary dimensions by which individuals created their racial categories. There is little evidence that lip or nose size substantially influenced informants' racial calculus. A minor exception is white faces with larger noses, which are distributed farther from the core. Thus, while still identified as branco, these faces were slightly "less" branco than others, resulting in them pulling slightly toward the sarará category. Overall, however, white faces with straight or wavy hair were identified as branco. White faces with kinky hair were labeled as sarará. Medium and dark skin faces with kinky hair are identified as negro. The category of moreno includes medium and dark-skinned individuals with straight or wavy hair. An interesting exception are women with medium or dark skin and straight hair. Many informants grouped these individuals with morenos, yet a number of them also labeled these individuals as appearing more "indio" or indigenouslooking_ often attributed to these faces' dark skin and long straight black hair.

Various measures of fitness are available for pile-sort data. As mentioned above, stress is a measure of distortion in the MDS diagram. A two-dimensional MDS that contains 72 objects should have a stress below 0.384 for the patterned relationship between objects to be significant at the 0.01 level. In Figure 2, the stress level is 0.147 , indicating that there is a less than $1 \%$ chance that this arrangement is random and without structure.

A second means of testing for structure in the pile-sort data is through cultural consensus analysis (Romney et al. 1986). Here, rather than an aggregate similarity matrix being constructed using the faces' assigned categories, it is constructed by aggregating how similar each informant's responses are to those of every other informant. This respondent-byrespondent similarity matrix can then be subjected to factor analysis (via ANTHROPAC) to determine if a single factor significantly explains most of the variance of the sample's responses. Although this approach does violate some of the assumptions of formal consensus analysis (Weller 2007), it is useful for providing an estimate of the amount of sharing among informants (Gravlee et al. 2017; see also Bernard 2018). The sample 


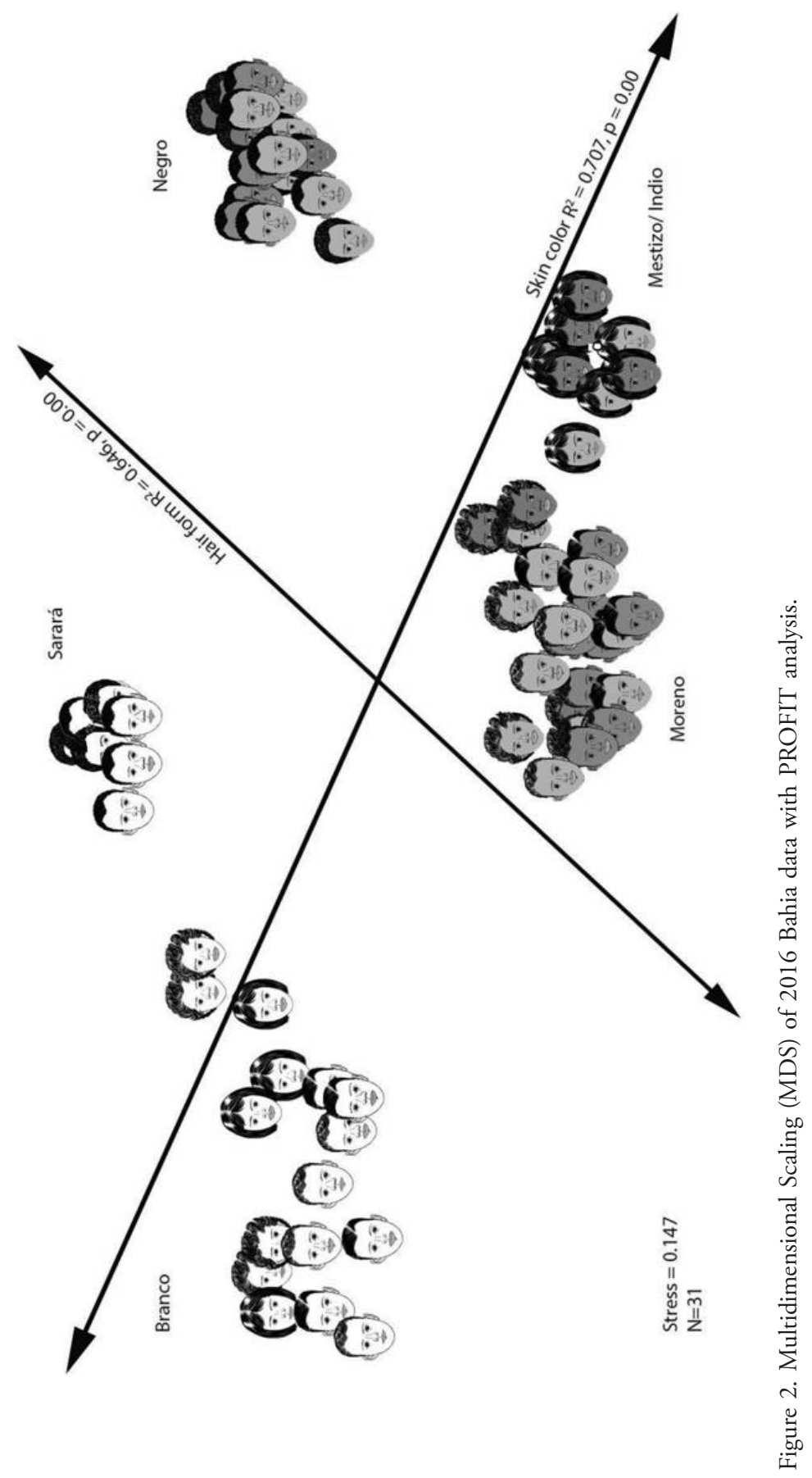

This content downloaded from 129.123.124.107 on June 10, 2019 10:13:32 AM 
of 31 informants included in the pile sort yielded an eigenvalue ratio of 3.38 and an average competency of 0.58 , with no negative scores, indicating that despite some interpersonal variation, this sample of Bahians sorted these 72 faces in a significantly similar fashion.

\section{DISCUSSION OF FINDINGS}

The assertion that Brazil is a racial democracy marked by racial exceptionalism relies on the idea that there is no bipolar, black-white color divide, and that there is substantial ambiguity in the distinctions between all racial categories (see Collins 2007). Yet, other studies have suggested that Brazil racial categories are much more structured, even to the point that race in Brazil is essentially constructed along white-nonwhite divides (e.g., Sheriff 2001). The analysis presented here does suggest that Bahians have a clearly demarcated classification scheme of raça that is on a negro-branco continuum. Harris originally concluded that "on the basis of recent studies carried out in Bahia, I am now of the opinion that we shall never be able to state the general cognitive formula by which particular Brazilians assign a racial identity to themselves, or by which particular Brazilians are assigned a racial identity by others" (1964:23). Yet, he lacked modern statistical methodologies to formally test this conclusion. Brazilian racial calculus may be complicated, but there is a definitive cognitive logic shared among the population.

The data Harris collected in the 1960s do show evidence of systematic ordering. Byrne and Forline (1997) found evidence of regional patterning in a cultural consensus analysis of the original data. In the MDS analysis of Harris's published data, we find evidence that there is observable patterning even among the larger sample of individuals. Informants labeled the faces in a similar enough fashion that subsequent multidimensional scaling is able to clearly sort the faces into five general groupings, likely based on skin color and hair type. In fact, the results match remarkably not only with our field school data but also with Sanjek's (1971) research. Sanjek found that the upper and lower limits of skin color (black and white) and hair texture (kinky and straight) variability had greater salience in identifying specific racial classifications (negro and branco, respectively). Intermediate forms, however, are more variable, resulting in numerous and sometimes fluid racial identities. In a retroactive MDS analysis of Sanjek's data, similar to the approach we apply to Harris, Jones (2009) finds that Sanjek's informants labeled the facial drawings into four primary groups (negro/preto, brancol alvo, sararálaracuabo, and moreno/caboclo/cabo verde), arranged by skin color and hair type. A high level of consensus was found within the contrasting negro and branco groups, whereas assignment to the intermediate moreno group showed the most variability.

Our own recent data from our Bahian cultural consensus and MDS analyses support the finding that classifications of race in Brazil are bipolar (along the extremes of variation) with structured ambiguity for intermediate forms. We find that despite generating 62 unique terms to describe 72 faces, only three root terms (negro, branco, and an intermediate form, mestiço) account for $65 \%$ of the identifications. Similarly, the 
cultural consensus analysis indicates that, with few exceptions, the culturally agreed upon identification for most cards is either negro or branco. Although this agreement reaches the threshold of "consensus," it does not mean that the domain is without variation. In fact, approximately one-third of faces have a plurality below 33\%, suggesting that fluidity and ambiguity is common rather than the exception. Yet, when overlaid with the MDS data, we see that ambiguity is still patterned by hair type and skin color. Faces with kinky hair and light skin are identified as sarará, and darker skin with straight or wavy hair is often identified as moreno, mestiço, or occasionally, indio (particularly the females, given their longer hair).

Analyses of the labeling and sorting tasks show that the phenotypic traits our Bahian informants used to designate racial identity were both skin color and hair form, replicating the early conclusions of both Harris and Sanjek, but also of recent studies, such as Gravlee's in Puerto Rico. The similarities of Harris's and Sanjek's data with our own suggest that the overall Brazilian calculus of race has remained relatively steady despite some minor fluctuations in use of terms. Further, comparisons with Gravlee's and Jones's data suggest the racial calculus of Brazil may not be unique compared with other parts of Latin America that experienced similar historical processes accompanied by rigid social and class hierarchies. To that point, Brazilian (along with other Latin American) uses of raça and cor may be largely synonymous in terms of generic labeling of unknown individuals. There are anecdotal claims to cor being more of a social than a racial class indicator. Narratives of dinheiro embranquece suggest that social and cultural capital, such as education, income, employment, and even the color of one's spouse, may alter the cor of a Brazilian. These accounts may be more exceptions, however, than evidence of alternative cultural systems. In fact, Harris thought that class and other social markers for cor may be overstated, particularly for initial impressions and sorting of individuals (that is, of strangers whose class, education, and background are not readily known). In other words, when dealing with strangers and others in public settings, the difference between cor (as a phenotype and social class marker) and raça (as a racial class marker) may be minimal.

\section{Relation of Findings to Brazilian Society}

The point here is not so much to cast out narratives of Brazilian race and nationhood, but to problematize them. Here, the Brazilian concept of individuo vs. pessoa, or kin/kith vs. stranger, becomes instructive. Brazilians emphasize the distinction of these two terms: a pessoa is someone who has a biography, a reputation-in other words, social and cultural capital; an individuo is a stranger, or someone who is just another citizen, an amorphous face in the crowd. Of course, the distinction between these two categories depends on the observer, as shown in the following phrases: "Você sabe com quem está falando?" (Do you know who you are talking to?) and "Aos amigos, tudo, aos inimigos, a lei" (For my friends, everything; for my enemies, the law) (see DaMatta 1991). For racial classification, this means that for friends and acquaintances, 
the more complicated racial calculus of including social and class indicators may come into play. For strangers, however, the phenotypic appearance is the only thing observers have to classify naturally occurring variation within culturally constructed categories such as gender, age, and race. Racial phenotypes, particularly around skin color and hair form, are viewed as important and essential qualities of the different racial typologies in Brazil. In a racially stratified country such as Brazil, what matters most is not one's self-identification but how they are classified by third parties (Bailey 2002).

Anthropologist Francisco Gil-White (2001:226) criticized the earlier Harris study, noting that in Brazil, "appearance is not the criterion for categorization, although we may use appearances to guide our first guess as to where a given object belongs." As discussed above in terms of individuo and pessoa, that is exactly the point: implicit bias based on appearance does inform our initial reactions to strangers in public settings during the course of daily life. Such interactions can and do have important social, political, and health ramifications. In the state of Sáo Paulo, for instance, negros are 3 times more likely to be killed by police than brancos (Reis 2014), and in all of Brazil negros are 2.5 times more likely to be the victims of homicide (Cerqueira et al. 2017). In another example documented by Michael Hanchard (1994:165):

Ana Flávia Peçanha de Azeredo, a nineteen-year-old college student, was accosted and punched in the face by a forty-year-old woman and her eighteenyear-old son in the service elevator of an apartment building where Ms. Peçanha was visiting a friend. The physical assault was the result of an argument between the three over Ana Flávia's use of the elevator. The mother and son did not like the fact that this young black woman not only had entered their building and held up the social elevator to talk to a friend, forcing them to use the service elevator, but also that she had dared tell them to respect her after they informed her that "black and poor don't have a place here" in the building where they lived.

Unbeknownst to the assailants, Ana was the daughter of the governor of the state of Espírito Santo. Ana never had the chance to ask if they "knew who they were talking to" or to establish herself as a pessoa person rather than an individuo. Rather, her presence in this public space was constrained because of her phenotypic appearance as a member of a subordinate group and not her own individual biography. Indeed, for many Brazilians, the racial calculus in their country has been much more dichotomous than what the myth of "racial democracy" suggests. While money may whiten and social status may influence cor, for most interactions it is also true that "blackness taints" (Hanchard 1994:180).

The meanings of whiteness, blackness, and shades in between shape the racial dimensions of other public agendas as well. Just over 10 years ago, Brazil began offering 
an affirmative action program for university placement. This was and remains a very controversial program, which sets up admissions quotas to federal universities based on cor and raça. The University of Brasília (UNB, one of the most prestigious public universities in Brazil) was the first public institution to adopt racial quotas in its selection process in 2004. Since then, other Brazilian institutions of higher education have decided to reserve a percentage of admissions for underrepresented racial groups. On the one hand, the existence (and necessity) of an affirmative action program casts doubt on the myth of a "racial democracy" and equality. On the other hand, it begs the question of how the miscegenation of the Brazilian social body can have authoritative racial boundaries, along with the question of how to ensure that racial quotas are met and respected.

The question of how society racially identifies its citizens has real structural implications. For example, in 2007, Alan Teixeira da Cunha and his identical twin brother Alex Teixeira da Cunha applied to UNB using the racial quota system. Under this program, 20\% of university admissions are reserved for negros and pardos. Alan and Alex are the sons of a black father and a white mother and felt that they qualified for the program. However, the selection committee in charge of the affirmative action policy, without knowing Alan and Alex were twin brothers, accepted Alan's application as pardo and rejected Alex's application, determining him to be branco (Zakabi and Camargo 2007). Partially due to this controversy, the federal government passed a law (Law 12.711, 29 August 2012) that rejected race-based admission standards and instituted one that privileged public school students (and, by proxy, lower-income Brazilians, who are predominately, though not exclusively, darker skinned).

The point here is that this was not the first time Brazil has struggled with the question of authentic race, nor will it be the last. Even today, land rights remain an essential concern of many Brazilian communities. Brazil's 1988 constitutional reform gave land rights to historically dislocated communities, such as indigenous peoples, as well as ancestors of the quilombos (hinterland communities settled by former and escaped African slaves) (Wade 2010). Yet, mining and logging corporations, along with Brazil's state and federal governments, are challenging these claims, in part by asking who the authentic and legal recipients of these lands are (see French 2009). Questions of racial identity such as "Who is authentically black? Who is indigenous?" do not have simple answers. Etic classification schemes and dichotomized (white, nonwhite) or trichotomized (branco, moreno, negro) categories may differ drastically from emic and self-ascribed labels (Byrne et al. 1995). And recent genetic studies suggest that brown and black Brazilians may have nearly as much, if not more, European genomic ancestry than either African or Amerindian ancestry. This indicates that genomic ancestry is an inadequate marker for cor (Santos et al. 2009; see also Pimenta et al. 2006). Rather, Brazilian conceptions of cor and raça are cultural constructs masquerading as reified biological or individual quality (see Marks 1994). Critically, however, these racial categories have life-affecting implications. In order to see how race shapes lives, it is first necessary to understand how society assigns racial identity to its people. 


\section{Brief Reflection on Methodology}

One critique of the methodology used here is that it relies on black and white drawings, rather than color photographs, to ascertain racial categories (see Gil-White 2001). The trait variations on the cards (skin, hair, nose, and lips) bias the sorting by only those dimensions. Although we can only test on these variables, use of photographs would introduce variation that cannot be controlled. Instead, the systematic use of variables allows for the structured cognitive methodologies used here and permits the retroactive application of methods on old datasets. The development of cognitive anthropological methodologies, including cultural domain analysis, cultural consensus, and cultural consonance, has allowed researchers to test what is often assumed in anthropological studies: a cultural domain is meaningfully constructed and shared among members of a population.

When Harris conducted his study almost 50 years ago, these methodologies were in their infancy, and many of the statistical analyses were accessible only with the most sophisticated computer mainframes. The creation of programs such as ANTHROPAC and UCINET gives researchers greater access to sophisticated cognitive anthropological methods. This not only permits new studies on a range of cultural phenomena, it also allows for the reexamination of past data (e.g., Byrne and Forline 1997; Jones 2009; see also Gravlee et al. 2003). In these cases, such structured approaches provide an extra layer of verification to the induced observations of the researcher. In the case presented here, these methods have allowed us to see structure where there was assumed to be none, and they have allowed us to compare how Brazilian models of race have remained largely consistent over the decades.

\section{CONCLUSION}

Brazil has been called a country of contradictions (Vincent 2003; Fontes et al. 2014; Jones and de Pinho 2006). It is a country of incredible wealth and abject poverty. Its landscape has near limitless potential, if only the country were not mired in nepotism and corruption. Brazilians confound locals and foreigners alike with their distinction of individuo and pessoa, and with their promise of a racial paradise predicated on a fluid and mercurial nature of raça. Given the unique history of Brazil, it is perhaps unsurprising that this narrative has taken root. The people of Brazil are a crossroads of humanity in which populations from clinal extremes came together to make a nation. The system of racial identity in Brazil is not as chaotic as the myth perpetuates, and the encouragement of a "racial democracy" in Brazil did not create a color-blind society. The racial calculus that Brazilians employ essentially functions along a black-white divide, with some moderate ambiguity in intermediate forms that is nevertheless patterned by secondary facial features. Modern cognitive anthropological methods enable new perspectives on these emic racial categorizations. Such patterns of emic cultural knowledge may go unrecognized if not for the continued applications and development of new anthropological methods (see Byrne and Forline 1997; Gravlee 2005). Given that race 
is still viewed as a biological fact in many parts of the world, it is important to reflect on the cultural construction of race-how people in a nation are carved up into these pseudo-biological, essentialized groups. Only then can we start to deconstruct popular notions of "race."

\section{NOTE}

Special thanks to Felicity Renee Hughes, Ryan Jensen, Francia Y. Solis Gil, Juan Jarlin De Leon Divison, Jairo David Arias Feliz, Kylie Searle, Brieann Charlesworth, and Caitlin Johnson Robertson for their work and participation in the USU International Initiative. Thanks to Rose and everyone at Pousada des Arts for being our home away from home. And appreciation to the College of Arts and Sciences at Utah State University for funding via the International Initiative.

\section{REFERENCES CITED}

Bailey, Stanley R. 2002. The race construct and public opinion: Understanding Brazilian beliefs about racial inequality and their determinants. American Journal of Socioloogy 108(2): 406-39.

2008. Unmixing for race making in Brazil. American Iournal of Sociology 114(3) 577-614. 2009. Legacies of race: Identities, attitudes, and politics in Brazil. Palo Alto: Stanford University Press.

Bailey, Stanley R., Mara Loveman, and Jeronimo O. Muniz. 2013. Measures of "race" and the analysis of racial inequality in Brazil. Social Science Research 42:106-19.

Baran, Michael D. 2007. "Girl, you are not morena. We are negras!": Questioning the concept of race in southern Bahia, Brazil. Ethos 35(3):383-409.

Baran, Michael, and Paulo Sousa. 2001. On the possibility of different sorts of racial categories. Lournal of Cognition and Culture 1(3):271-81.

Bernard, H. Russell. 2011. Research methods in anthropology: Qualitative and quantitative approaches. Lanham, MD: Rowman Altamira.

- 2018. Research methods in anthropology: Qualitative and quantitative approaches, sixth edition. Lanham, MD: Rowman \& Littlefield.

Bernard, H. Russell, and Clarence C. Gravlee, eds. Handbook of methods in cultural anthropology, second edition. Lanham, MD: Rowman and LIttlefield.

Borgatti, S. P., M. G. Everett, and L. C. Freeman. 2002. UCINET for Windows: Software for social network analysis. Harvard, MA: Analytic Technologies.

Brand, Donald D. 1941. A brief history of anthropology in Brazil. New Mexico Anthropolooist 5(4): 99-150.

Brazill, Timothy J., and Bernard Grofman. 2002. Factor analysis versus multi-dimensional scaling: Binary choice roll-call voting and the US Supreme Court. Social Networks 24(3): 201-29.

Burdick, John. 1998. Blessed Anastácia: Women. race, and popular Christianity in Brazil. New York: Routledge.

Byrne, Bryan, and Louis Forline. 1997. The use of emic racial categories as a tool for enumerating Brazilian demographic profiles: A re-analysis of Harris's 1970 Study. Boletim do Museu Paraense de História Natural e Ethnographia (Antropologia) 13(1):3-25. 
Byrne, Bryan, Marvin Harris, Josildeth Gomes Consorte, and Joseph Lang. 1995. What's in a name? The consequences of violating Brazilian emic color-race categories in estimates of social well-being. Iournal of Anthropological Research 51(4):389-97.

Carvalho, José Alberto Magno de, Charles H. Wood, and Flávia Cristina Drumond Andrade. 2004. Estimating the stability of census-based racial/ethnic classifications: The case of Brazil. Population Studies 58(3):331-43.

Caulkins, Douglas, and Susan B. Hyatt. 1999. Using consensus analysis to measure cultural diversity in organizations and social movements. Field Methods 11(1):5-26.

Cerqueira, Daniel, Renato Sergio de Lima, Samira Bueno, Luis Iván Valencia, Olaya Hanashiro, Pedro Henrique G. Machado, and Adriana dos Santos Lima. 2017. Atlas da Violência 2017. Rio de Janeiro: Ipea e FBSP.

Collins, John F. 2007. Recent approaches in English to Brazilian racial ideologies: Ambiguity, research methods, and semiotic ideologies. A review essay. Comparative Studies in Society and History 49(4):997-1009.

DaMatta, Roberto. 1991 A Casa e a Rua. Rio de Janeiro: Guanabara Koogan.

1997. Notas sobre o racismo à Brasileira. Multiculturalismo e racismo: Uma comparaçấo Brasil-Estados Unidos. Brasilia: Paralelo 15:69-74.

D’Andrade, Roy G. 1995. The development of cognitive anthropology. Cambridge: Cambridge University Press.

Dengah, H. J. François. 2014. How religious status shapes psychological well-being: Cultural consonance as a measure of subcultural status. Social Science and Medicine 114:18-25.

Dressler, William W. 2017. Culture and the individual: Theory and method of cultural consonance. New York: Routledge.

Dressler, William W., Mauro C. Balieiro, and Jose Ernesto Dos Santos. 2015. Finding culture change in the second factor: Stability and change in cultural consensus and residual agreement. Field Methods 27(1):22-38.

Dugard, Pat, John B. Todman, and Harry Staines. 2010. Approaching multivariate analysis: A practical introduction. New York: Routledge.

Edmonds, Alexander. 2010. Pretty modern: Beauty, sex, and plastic surgery in Brazil. Durham, NC: Duke University Press.

Ferreira, Antônio Honório. 2012. Classificação racial no Brasil, por aparência ou por origem? $36^{\text {th }}$ Encontro Anual da Anpocs Gt30 - Relações raciais: desigualdades, identidades e políticas públicas. https://anpocs.com/index.php/papers-36-encontro/gt-2/gt30-2. Accessed September 11, 2017.

Fontes, Paulo, Paulo Roberto Ribeiro Fontes, and Bernardo Buarque De Hollanda. 2014. The country of football: Politics, popular culture and the beautiful game in Brazil. London: Hurst \& Company.

Freese, Jeremy, and David Peterson. 2017. Replication in social science. Annual Review of Socioloogy 43:147-65.

French, Jan Hoffman. 2009. Legalizing identities: Becoming black or Indian in Brazil's Northeast. Chapel Hill: University of North Carolina Press.

Fry, Peter. 2000. Politics, nationality, and the meaning of "race" in Brazil. Daedalus 129(2): 83-116.

Gil-White, Francisco J. 2001. Are ethnic groups biological "species" to the human brain? Essentialism in our cognition of some social categories. Current Anthropology 42(4):515-53. 
Gravlee, Clarence C. 2005. Ethnic classification in southeastern Puerto Rico: The cultural model of "color." Social Forces 83(3):949-70.

Gravlee, Clarence C., H. Russell Bernard, and William R. Leonard. 2003. Heredity, environment, and cranial form: A reanalysis of Boas's immigrant data. American Anthropologist 105 (1):125-38.

Gravlee, C. C., Maxwell, C. R., Jacobsohn, A., \& Bernard, H. R. 2017. Mode effects in cultural domain analysis: Comparing pile sort data collected via internet versus face-to-face interviews. International Iournal of Social Research Methodolooy 21(2):165-76.

Guimarães, Antonio Sérgio Alfredo. 2003. Notas sobre raça, cultura e identidade na imprensa negra de São Paulo e Rio de Janeiro, 1925-1950. Afro-Ásia 30:247-69.

Gulbas, Lauren E. 2013. Embodying racism: Race, rhinoplasty, and self-esteem in Venezuela. Qualitative Health Research 23(3):326-35.

Hanchard, Michael. 1994. Black Cinderella? Race and the public sphere in Brazil. Public Culture 7(1):165-85.

Handwerker, W. Penn. 2001. Quick ethnography: A guide to rapid multi-method research. Walnut Creek. CA: AltaMira.

2002. The construct validity of cultures: Cultural diversity, culture theory, and a method for ethnography. American Anthropologist 104(1):106-22.

Harris, Marvin. 1964. Racial identity in Brazil. Luso-Brazilian Review 1(2):21-28. 1970. Referential ambiguity in the calculus of Brazilian racial identity. Southwestern Journal of Anthropology 26(1):1-14.

Harris, Marvin, and Conrad Kottak. 1963. The structural significance of Brazilian racial categories. Sociologia 25(3):203-8.

Hasenbalg, Carlos. 1985. "Race and socioeconomic inequalities in Brazil," in Race, class and power in Brazil. Edited by Pierre-Michel Fontaine, pp. 25-41. Los Angeles: Center for AfroAmerican Studies, University of California.

Holland, Dorothy, and Naomi Quinn, eds. 1987. Cultural models in language and thought. New York: Cambridge University Press.

Holston, James. 2008. Insurgent citizenship: Disjunctions of democracy and modernity in Brazil. Princeton, NJ: Princeton University Press.

Hordge-Freeman, Elizabeth. 2015. The color of love: Racial features, stigma, and socialization in black Brazilian families. Austin: University of Texas Press.

Hruschka, Daniel J., Lynn M. Sibley, Nahid Kalim, and Joyce K. Edmonds. 2008. When there is more than one answer key: Cultural theories of postpartum hemorrhage in Matlab, Bangladesh. Field Methods 20(4):315-37.

IBGE (Instituto Brasileiro de Geografia e Estatística). 2010. Censo Demográfico 2010: Características Gerais da População, Religião e Pessoas com Deficiência. http://www.ibge.gov.br /home/estatistica/populacao/censo2010, accessed July 20, 2017.

Jones, Doug. 2009. Looks and living kinds: Varieties of racial cognition in Bahia, Brazil. Lournal of Coonition and Culture 9(3):247-69.

Jones, Geoffrey, and Ricardo Reisen de Pinho. 2006. Natura: Global beauty made in Brazil. Harvard Business School Case 807-029.

Kottak, Conrad Phillip. 1967. Race relations in a Bahian fishing village. Luso-Brazilian Review $4(2): 35-52$. 
Lacy, M. G., J. G. Snodgrass, Mary Meyer, H. J. François Dengah II, and Noah Benedict. 2018. A formal method for detecting and describing cultural complexity: Extending classical consensus analysis. Field Methods 30(3):241-57.

LeCompte, Margaret D., and Judith Preissle Goetz. 1982. Problems of reliability and validity in ethnographic research. Review of Educational Research 52(1):31-60.

Loveman, Mara. 1999. Is "race" essential? American Sociolooical Review 64(6):891-98.

Marks, Jonathan. 1994. Black, white, other. Natural History 103(12):32-35.

Mikulak, Marcia L. 2011. The symbolic power of color: Constructions of race, skin-color, and identity in Brazil. Humanity \& Society 35(1-2):62-99.

Miranda, Vítor. 2015. A resurgence of black identity in Brazil? Evidence from an analysis of recent censuses. Demographic Research 32:1603-30.

Pimenta, Juliana R., Luciana W. Zuccherato, Adriana A. Debes, Luciana Maselli, Rosângela P. Soares, Rodrigo S. Moura-Neto, Jorge Rocha, Sergio P. Bydlowski, and Sérgio DJ Pena. 2006. Color and genomic ancestry in Brazilians: A study with forensic microsatellites. $\underline{\mathrm{Hu}-}$ man Heredity 62(4):190-95.

Reis, Thiago. 2014. Taxa de negros mortos pela polícia de SP é 3 vezes a de brancos, diz estudo. Globo. http://g1.globo.com/sao-paulo/noticia/2014/03/taxa-de-negros-mortos -pela-policia-de-sp-e-3-vezes-de-brancos-diz-estudo.html. Accessed July 14, 2017.

Robinson, Eugene. 1999. Coal to cream: A black man's journey beyond color to an affirmation of race. New York: Free Press.

Romney, A. Kimball, Susan C. Weller, and William H. Batchelder. 1986. Culture as consensus: A theory of culture and informant accuracy. American Anthropologist 88(2):313-38.

Sanjek, Roger. 1971. Brazilian racial terms: Some aspects of meaning and learning. American Anthropolooist 73(5):1126-43.

Santos, Ricardo Ventura, Peter H. Fry, Simone Monteiro, Marcos Chor Maio, José Carlos Rodrigues, Luciana Bastos-Rodrigues, Sérgio DJ Pena, et al. 2009. Color, race, and genomic ancestry in Brazil: Dialogues between anthropology and genetics. Current Anthropolooy 50:787-819.

Schwartzman, Luisa Farah. 2007. Does money whiten? Intergenerational changes in racial classification in Brazil. American Sociological Review 72(6):940-63.

Sheriff, Robin E. 2001. Dreaming equality: Color, race, and racism in urban Brazil. New Brunswick, NJ: Rutgers University Press.

Shore, Bradd. 1996. Culture in mind: Cognition, culture, and the problem of meaning. New York: Oxford University Press.

Silva, Nelson do Valle. 1985. "Updating the cost of not being white in Brazil," in Race, class and power in Brazil. Edited by Pierre-Michel Fontaine, pp. 42-55. Los Angeles: Center for Afro-American Studies, University of California.

Skidmore, Thomas E. 2009. Brazil: Five centuries of change, second ed. New York: Oxford University Press.

Snodgrass, Jeffrey G., Michael G. Lacy, H. J. François Dengah II, and Jesse Fagan. 2011. Cultural consonance and mental wellness in the World of Warcraft: Online games as cognitive technologies of "absorption-immersion." Cognitive Technology 16(1):11-23.

Soares, Sergei. 2008. "A demografia da cor: a composição da população brasileira de 1890 a 2007," in As políticas públicas e a desigualdade racial no Brasil, pp. 97-117. Brasília: IPEA. 
Sturrock, Kenneth, and Jorge Rocha. 2000. A multidimensional scaling stress evaluation table. Field Methods 12(1):49-60.

Telles, Edward E. 2003. Racismo à brasileira: uma nova perspectiva sociologica. Rio de Janeiro: Relume Dumará.

2014. Race in another America: The significance of skin color in Brazil. Princeton, NJ: Princeton University Press.

Telles, Edward E., and Nelson Lim. 1998. Does it matter who answers the race question? Racial classification and income inequality in Brazil. Demooraphy 35(4):465-74.

Vincent, Jon S. 2003. Culture and customs of Brazil. Westport, CT: Greenwood Press.

Wade, Peter. 2010. Race and ethnicity in Latin America, second edition. New York: Pluto Press.

Wagley, Charles, ed. 1952. Race and class in rural Brazil. Paris: UNESCO.

Weller, Susan C. 2007. Cultural consensus theory: Applications and frequently asked questions. Field Methods 19(4):339-68.

Wood, Charles. 1991. "Categorias censitarias e classificações subjetivas de raça no Brazil," in Desigualdade racial no Brasil contemporâneo. Edited by Peggy Lovell. Belo Horizonte: MGSP Editores.

Yelvington, Kevin A. 2001. The anthropology of Afro-Latin America and the Caribbean: Diasporic dimensions. Annual Review of Anthropology 30(1):227-60.

Zakabi, Rosana, and Leoleli Camargo. 2007. Raça não existe. Revista Veja 2011. http://www .redeacaoafirmativa.ceao.ufba.br/uploads/veja_materia_2007_RZakabi_LCamargo.pdf 